DOI: $10.5216 /$ racs.v4.59074

\title{
Educação para manejo do mundo
}

Gersem Baniwa $^{1}$

RESUMO

Este artigo trata da ideia de "educação para manejo do mundo" que foi o tema de minha pesquisa doutoral publicada em 2011. A ideia central é a educação indígena Baniwa como processo formativo e transformativo, cujo propósito é o manejo do mundo no sentido de compreendê-lo para respeitá-lo e dele garantir o equilíbrio da vida e da existência humana e da natureza. Conhecimento para o manejo do mundo e da natureza possibilita a construção permanente de uma vida e existência humana desejável e sustentável, baseada no princípio filosófico indígena de bem viver da natureza e com a natureza, contrapondo-se à ideia globalizada do conhecimento para exploração, destruição e dominação da natureza e da vida. De acordo com o pensamento indígena de manejo e domesticação permanente da vida e do mundo, o poder não está nas mãos das sociedades humanas, mas na composição da natureza, ao contrário do pensamento ocidental globalizado, em que o poder político, histórico e civilizatório está nas mãos das sociedades humanas.

PALAVRAS-CHAVE: Educação. Educação escolar. Educação indígena e manejo do mundo.

\section{Ikadzeekataa kakhettiapani pamatsiatakaro Hekoapi}

\section{RESUMO EM BANIWA}

Kwa ampinima waa unheen mayé yamaan ara resé, sesé waa asikai akuaarama amunham ramekuera se doutorado, assui anpinima aé yepê livro upé 2011 ramemkwera. Kwa yamanduari-sá umbué yandé mayé ya viveri arama puranga kwa yane ara irumu. Yavivei arama puranga kwa panhé ya ara upé asuí irumu. Kwa yamanduari-sá yandé Baniwaitá amuripi turusú kua mayé kariwaitá tamanduari tamunhamunham asuí tayuká kwa yane ara, yaneretama. Kwa Baniwa tamanduari sá upé awá umundu kwa mundo upé aité kwa ara yaraitá, umbaa miraitá, mayé kwa kariwaitá umanduari sá.

YANEENGA RETEWAÁ: Yakwa-sá. Escola ukua-sá. Yandé índio-itá yakua-sá asuí kua mayé ya viveri puranga kwa yané ara irumu.

\footnotetext{
${ }^{1}$ Mestre e doutor em Antropologia Social pela Universidade de Brasília (UNB). Professor Adjunto do Departamento de Educação Escolar Indígena da Faculdade de Educação da Universidade Federal do Amazonas (DEEI/FACED/UFAM). Professor indígena do povo Baniwa. Manaus, AM, Brasil. E-mail: gmapolero@gmail.com.
} 


\title{
Education for the Management of the World
}

\begin{abstract}
This article is about "education for the management of the world" that was the subject of my doctoral research published back in 2011. The main idea is the Baniwa indigenous education as a formative and transformative process which its aim is to manage the world in a way to understand it, respect it and ensure the balance of life, human existence and nature. The knowledge for the management of the world and nature enables the permanent construction of a desirable and sustainable human life and an existence based on the indigenous philosophical principle of well-being of nature and with the nature, opposing the globalized idea of knowledge for exploration, destruction and domination of nature and life. According to the indigenous thinking on the management and permanent domestication of life and the world, the power is not in the hands of human societies, but in the composition of nature, unlike Western globalized thinking, where political, historical and civilizing power are in the hands of human societies.
\end{abstract}

KEYWORDS: Education. School education. Indigenous education and world management.

\section{Apresentação}

Este texto é resultado de uma palestra proferida em 17 de novembro de 2014, no "Curso de especialização em educação intercultural e transdisciplinar: gestão pedagógica", do Núcleo Takinahakỹ de Formação Superior Indígena (NTFSI) da Universidade Federal de Goiás (UFG), sob a coordenação da Professora Maria do Socorro Pimentel da Silva que, na ocasião, destacou a importância de se construir um Projeto Político Pedagógico com os/as professores/as indígenas, cujas discussões visam repensar o sentido da escola e as verdadeiras demandas que cada comunidade tem à luz de questionamentos como: Qual é a escola que os/as professores/as indígenas e suas respectivas comunidades realmente querem? Como repensar a escola? Como pensar a educação contextualizada? Qual é o lugar de contextualização das políticas pedagógicas específicas, interculturais e diferenciadas? Questões estas que fazem um apelo para uma reflexão profunda no que se refere à produção de projetos políticos pedagógicos e, para tanto, as discussões daquele evento deveriam ser realmente efetivas e produtivas para os povos indígenas, para a escola, para a universidade e para a sociedade brasileira em geral. 


\section{Educação para manejo do mundo}

A educação escolar indígena é um campo que não possui metodologias acabadas, até porque é recente para os povos indígenas brasileiros, o que eleva a importância da troca de conhecimentos como esta, proporcionada por este espaço de diálogo. Classifico este texto como uma provocação cujo título "Educação para o manejo do mundo" é de minha tese de doutorado (LUCIANO, 2013). A provocação tem como objetivo central chamar nossa atenção para a compreensão da educação indígena como formas próprias e milenares de lidar com o mundo e com a natureza, contrapondo frontalmente à ideia etnocêntrica e eurocêntrica de que os povos indígenas vêm sendo educados, como se não tivessem antes e sempre sua educação própria (LUCIANO, 2013).

Nossa experiência de 30 anos de luta pela causa indígena nos autoriza afirmar que é necessário pensar melhor sobre o que nos é imposto pelo mundo do branco, especialmente, pela escola e pela universidade. A ciência acadêmica ocidental divide e opõe índio e branco, homem e mundo, sociedade e natureza, corpo e espírito, bem e mal, rico e pobre, gordo e magro, conhecimento tradicional ou popular e conhecimento científico e assim por diante. É necessário a gente entender bem esse tipo de pensamento e, principalmente, ter muito cuidado para não acreditar nele como verdade absoluta. Os conhecimentos e pensamentos indígenas são muito diferentes e não se baseiam nesse dualismo por oposição. Acreditar e seguir indistintamente o pensamento ocidental na escola e na academia pode produzir estragos profundos irreversíveis para os nossos conhecimentos e modos de vida indígena.

Sabemos que os estudos na graduação e na pós-graduação ainda não garantem espaços institucionais adequados para os indígenas e seus distintos e numerosos conhecimentos e experiências de vida, pois o cartesianismo e o positivismo antropocêntrico reinantes nos programas, cursos e disciplinas continuam orientados e orientando pesquisas e teorias a partir da ideia frágil de "objetividade" da produção acadêmica, que induz ou mesmo seduz ao pensamento e atitudes perigosas de separação e distanciamento hierárquico do homem da natureza cósmica com suposto privilégio do primeiro sujeito homem e em detrimento do segundo sujeito natureza (SOUZA SANTOS, 2000).

A ciência ocidental induz os estudantes indígenas ao exercício de isolamento do homem do mundo e da natureza, ainda que como estratégia metodológica e isso provoca profundos dilemas existenciais, cosmológicos e epistemológicos aos indígenas que acreditam e se sentem membros inseparáveis e interdependentes da natureza cósmica. Quando a Ciência 
fala que é necessário sair e afastar-se do mundo concreto para então estudá-lo e conhecê-lo e os indígenas seguem, já estão rompendo com seus modos de vida, com suas culturas, com seus pensamentos tradicionais milenares. Essa separação dualista da natureza é muito nociva e perigosa para os modos de pensar e viver dos indígenas baseados fundamentalmente na organicidade, interdependência e holismo da natureza e do mundo como um todo (ESCOBAR, 2005).

Entendemos que é importante conhecer e compreender a Ciência Ocidental como um modo de pensar e viver entre tantos outros modos de pensar e viver existentes no mundo, dentre os quais os dos povos indígenas. É importante também reconhecer a importância histórica das grandiosas conquistas do conhecimento humano do ocidente europeu para toda a humanidade, mas não são os mais verdadeiros ou superiores e não são os únicos a produzirem tais proezas humanas no mundo. Outras civilizações humanas como os hindus, os chineses, os incas, os astecas, os povos indígenas em geral, os povos africanos também construíram e deixaram legados igualmente importantes para a humanidade de hoje, no campo do pensamento, da filosofia, da religião, das ciências, das técnicas e tecnologias.

A diversidade de pensamentos, de conhecimentos e de modos de vida é profundamente salutar à continuidade e sustentabilidade da vida no nosso planeta. É importante destacar que desde o momento em que o homem branco, por meio de sua ciência, começou a separar o homem da natureza, colocando-se acima dela como dominador, consumidor ou predador, aconteceram as piores coisas no mundo: desmatamento e queimadas intensas de grandes proporções, aquecimento global, enchentes e tsunamis, furacões, tufões devastadores, assoreamento e morte de rios e lagos, represas de mortes de peixes e assim por diante.

O homem branco considera a natureza inferior a ele e, por essa razão, quer fazer dela o que bem entender: estradas, hidroelétricas, desmatamento, assoreamento de rio, exploração predatória e insustentável dos recursos naturais, tais como madeira, pescados, minérios, extrativismo, porque não sente dor de consciência coletiva, orgânica e cósmica, e isso advém da separação do homem da natureza. Praticar grandes monoculturas não é um pensamento apenas dos políticos brancos, é pensamento do ocidente que está na universidade, na escola e na sociedade herdeira do ocidente europeu. A partir do momento em que acreditamos e adotamos os cânones artificiais de objetividade, imparcialidade, apolítica, neutralidade, impessoalidade e laicidade da ciência acadêmica, passamos a pensar igual como pensa o grande produtor de soja, cujo único interesse é ganhar e acumular dinheiro a qualquer custo e 
de qualquer forma, não importando as consequências de seus atos para a vida humana e a vida da natureza.

Nós indígenas pensamos a partir de nossos sentimentos e nossas crenças que estão sempre relacionados com a natureza e com o mundo das quais somos inseparavelmente partes (ESCOBAR, 2005). Vivemos em profunda interação e respeito com a natureza da qual dependemos para viver e, assim, reciprocamente, a natureza, por sua vez, precisa de nós como parte dela para estar em sua completude. O homem branco é alucinado pela exploração da natureza a qualquer custo e com propósitos pouco humanos e naturais. Neste momento, não podemos seguir o caminho apontado pelos pensamentos e conhecimentos científicos ocidentais e devemos sim adotar atitude de desobediência epistêmica em favor de nossas ciências, valores e crenças (MIGNOLO, 2008).

Assim, a função educativa dos povos indígenas é para manejar o mundo, não no sentido de dominar e subjugar, mas no sentido de compreender e alinhar-se a ele, ajudando-o e sendo ajudados. Compreender e alinhar-se à natureza de acordo com a sua dinâmica, racionalidade, lógicas e limitações e beneficiando-se de suas forças e potencialidades naturais e sobrenaturais sempre muito generosas, mas também muito justa, é função educativa primordial. Mas para alcançar a sabedoria e a sensibilidade humana é necessário ouvir, observar, compreender suas mensagens por meio de vozes (trovões, cantos), sons (ruídos fortes de cachoeiras, correntezas, ondas e banzeiros, ruídos de peixes no fundo do rio, ou de animais de caça no mato, som de aves revoando ou em repouso nas árvores, ou ainda o silêncio profundo no coração dos lagos e das florestas), eventos majestosos por vezes belos e outras vezes ameaçadores, assustadores e devastadores (tempestades, furações, tufões, tsunamis) e, por fim, deixar compenetrar-se e interpenetrar-se seguindo os seus ritmos, tempos, ciclos e forças. Assim, a vida é mais bem vivida com liberdade, segurança e sustentabilidade natural.

Os povos indígenas, talvez, sejam os maiores especialistas em ouvir, seguir e conhecer a natureza e, por esse motivo, sabem compreendê-la, beneficiar-se dela, mas também beneficiar a ela em sua luta por existência e sobrevivência. $\mathrm{O}$ som produzido e emitido por cada animal tem um sentido e significado. Cada ser, evento ou fato emite um som ou produz um fenômeno que pode indicar um pedido de socorro, de um convite a tempos de alegria e de abundância ou simplesmente indicando período ou ciclo de tempo da natureza (verão, inverno, sol, chuva, tempestade, cheia do rio, seca do rio, escassez ou fartura de peixe, caça, roça, tempo de doenças, saúde, de paz, de guerra, de fraternidade ou de ódio, de amizade ou 
de inimizade), identificado e indicando determinado espaço geográfico (terra firme, terra virgem, terra capoeira, terra fértil ou terra pobre, igapó, caatinga, campo, território de caça abundante ou não etc). Levi-Strauss observou isso assim que chegou na América e assim testemunhou a respeito:

\footnotetext{
As faculdades aguçadas dos indígenas lhes permitiram notar exatamente os caracteres genéricos de todas as espécies vivas, terrestres e marinhas, assim como mudanças, os mais sutis de fenômenos naturais, tais como os ventos, a luz e as cores do tempo, as ondulações ligeiras das vagas, as variações da ressaca, as correntes aquáticas e aéreas (LEVI-STRAUSS, 1989, p. 17).
}

A educação como manejo do mundo vem para contrapor a ideia de educação para manipulação, exploração, dominação e destruição do mundo, pois a ciência, embora busque a compreensão da natureza, é sempre para subjugá-la, dominá-la, explorá-la como se isso fosse possível em sua plenitude e, não para compreendê-la, respeitá-la, protegê-la e cuidá-la como algo tão imprescindível para a vida no planeta.

A ideia de manejo traz consigo outra ideia, a de domesticação. Manejo do mundo refere-se à capacidade sensível de compreensão e de alinhamento natural ao funcionamento orgânico da natureza e do mundo, enquanto domesticação refere-se à compreensão e domínio das instituições, atores e conhecimentos dominantes colonizadores, que à luz da capacidade de manejo, devem ser humanizadas, naturalizadas (alinhadas à natureza) e apropriadas complementariamente em benefício da vida humana, da natureza e do mundo. Ambos os conceitos fazem parte de um vocabulário estratégico colonial, mas aqui apropriado e revertido em estratégia de descolonização ou contra colonização cada vez mais adotadas pelos povos indígenas nos últimos anos.

Este Curso de Especialização em Educação Escolar Indígena é uma oportunidade rara, porque ainda são pouquíssimas as iniciativas desse gênero no Brasil. Os cursos de especialização voltados para as temáticas de interesse dos povos indígenas precisam se multiplicar abrindo novas abordagens teóricas, metodológicas e práticas relativas ao campo das temáticas indígenas. Nos últimos 20 anos tem havido importantes discussões sobre o que é educação escolar indígena e elas apontam para a necessidade de estabelecimento de outros horizontes, outras metas e métricas e outros objetivos sobre o que significa a educação escolar indígena que ainda é muito pouco discutida, inclusive, pelos próprios povos indígenas, para saber como lidar com a educação escolar dentro das aldeias. Esse é um debate que tem circulado nas academias e muito pouco nas comunidades indígenas. 
Nos últimos anos, os povos indígenas têm sido orientados a ter uma educação escolar específica e diferenciada. Mas que especificidade e diferenciação são essas? Há alguns avanços: as línguas indígenas deixaram de ser negadas e desvalorizadas. Nossas línguas passaram a ser valorizadas nos últimos anos, em alguns casos de forma concreta e em outros casos, pelo menos no discurso e nas letras das normas e documentos técnicos. Alguns povos, também, estão começando abrir as portas das salas de aula e das escolas para que os saberes indígenas tradicionais entrem e comecem a fazer parte dos currículos, das disciplinas, dos materiais didáticos e dos planos de ensino e de aula dos professores. Com isso, a prática de interculturalidade começa a ganhar forma, força e gosto, promovendo, enfim, a convivência e aplicação articulada e mutuamente complementar dos conhecimentos indígenas e dos conhecimentos científicos escolares. É importante lembrarmos sempre que a melhor forma de “domesticar” nós índios - domesticar aqui no sentido de dominação e tutela -, é fechando-nos em uma sala de aulas ou dentro das paredes, muros ou cercas da escola como fomos tratados ao longo dos 519 anos da nossa história de invasão e perversa colonização.

Em algumas escolas Baniwa, por exemplo, ainda encontramos "bancos e carteiras ou mesas coletivas" de madeira local onde as crianças estudam construídas pelas próprias comunidades, no lugar de carteiras modernas individualizadas fornecidas pelo poder público. Esses "bancos" com carteiras acopladas são muito importantes para manter o espírito coletivo e comunitário ancestral dos alunos. A escola foi e ainda é a principal responsável pela individualização, por exemplo, da carteira, do caderno, do lápis, do copo, da comida. Os Baniwa também ainda conservam a tradição das refeições comunitárias em que a comida é servida em panelas ou cuias grandes e as pessoas se servem usando a técnica sutil de enfiar a mão munida com pedaço de bejú na panela para içar um pedaço de carne a cada vez, habilidade que requer técnica apurada, caso contrário, o bejú se derrete instantaneamente impossibilitando carregar o pedaço de carne.

Em 2008, por ocasião da minha primeira passagem pelo Conselho Nacional de Educação (CNE) consegui que a Câmara de Educação Básica daquele Conselho realizasse um dia de sua reunião ordinária em uma aldeia no Alto Rio Negro que ainda vive de forma coletiva e tradicional. Fiz com que os colegas conselheiros e as conselheiras participantes pudessem perceber e viver, por um dia, a grande diferença e diversidade entre as culturas e os modos de vida existentes em nosso país e, especialmente, naquela região multiétnica e multicultural. Quando me perguntavam onde encontrar banheiro, constrangido, lhes informava que tinham duas opções: mato ou rio. Na hora de comer, perguntaram pelos pratos 
e talheres e, então, lhes orientavam para que seguissem o exemplo das pessoas da região. Tratava-se exatamente de comer usando bejú para pegar carne das panelas que estavam no meio do salão. Todos seguiram o exemplo ou pelo menos tentaram. Todos compartilharam da panela coletiva com seus pedaços de biju. Ao final da refeição, como manda a tradição, todos sentados ou em pé, postados em um único e grande circulo, 10 cuias de xibé pelo menos foram passando por cada um, de mãos em mãos e de boca em boca, iniciando no sentido relógio e concluído no sentido contrário. Xibé é uma bebida feita com farinha de mandioca, água ou vinho de açaí, bacaba ou patauá. Dessa vez, os conselheiros e as conselheiras e todos os demais participantes estavam com sorte, pois havia muitas cuias de xibé de açaí e bacaba, o que não é muito comum, mas, sem dúvida, assim, o xibé fica muito mais gostoso e nutritivo. Cada família levou da aldeia sua panela de comida, farinha, bejú e sua cuia de xibé para compartilhar com todos os visitantes, convidados e membros da aldeia, tornando o dia de trabalho e reunião muito produtivo e alegre.

A experiência foi muito positiva para demonstrar aos conselheiros e às conselheiras a diferença cultural e a distância da cultura ocidental para as culturas indígenas. Foi um dia rico, desafiador, mas de muita aprendizagem e vivência profunda de uma realidade específica e pouquíssima conhecida pelos brasileiros e pelo mundo. Não recebi nenhuma reclamação negativa dos conselheiros e das conselheiras que participaram da experiência, pelo contrário, ouvi e recebi muitos elogios, estranhamentos, sim, mas sempre no sentido pedagógico de aprendizagem, descoberta e novos conhecimentos antes ignorados.

É necessário compreender o que é diversidade cultural que não é ideia ou conceito. São modos de vida concretos vividos por milhares de pessoas, comunidades e povos com suas culturas, tradições, línguas, valores, saberes, conhecimentos e visões de mundo. Um dos lugares que mais reprime a diversidade cultural é a universidade, que só perde para as igrejas. Um dos maiores pecados que a universidade comete com os indígenas é quando ignora ou rechaça a espiritualidade, em benefício da separação homem/natureza/divindades. Para nós indígenas, a vida ganha sentido com a espiritualidade, muito diferente de como pensam os brancos. Para nós indígenas, todos os seres têm espírito. A própria natureza tem espírito. A natureza é espírito puro. A natureza é um grande espírito. O universo é um grande espírito.

Discutir interculturalidade sem levar em consideração essas questões de espiritualidades é nos limitarmos à artificialidade do conceito e da ideia de "objetividade" científica, tornando o mundo e a vida incompletas, incontroláveis, à deriva, portanto, irreconhecíveis, estranhas e perigosas. 
A saúde corporal e espiritual das pessoas e da própria natureza depende da relação dialógica, respeitosa, colaborativa e interdependente entre os espíritos que sustentam a existência dos seres e das coisas. A natureza é constituída de consciência e capacidade de sentimento e de ação e reação, por isso, se alegra diante de boas ações retribuindo igualmente com boas ações (fartura na pesca, na caça, na roça, de frutas, na saúde) ou se entristece com más ações e retribui com escassez de coisas.

A natureza é uma agência indomável, autônoma, autoconsciente, generosa e muito produtiva, mas, também reativa, defensiva e ofensiva. Sua reação diante de uma ameaça, desrespeito ou violência contra ela é autodefensiva na busca de garantir sua existência, sobrevivência, diante de sua limitude primordial. Essa concepção de natureza está muito distante do pensamento acadêmico dominante no mundo globalizado atual. A exploração destrutiva da natureza, em curso, põe em risco a própria capacidade de continuidade sustentável da vida humana e do planeta e que acontece porque o pensamento ocidental não considera a espiritualidade, agencialidade e finitude da natureza.

Para os Baniwa, as doenças existem porque o homem deixou de ter uma relação respeitosa com a natureza, em algum momento, e de alguma forma. Portanto, doenças humanas são resultados de não observância aos princípios de convivência e coexistência com a natureza. Como todos os seres são munidos de agências espirituais - espíritos do bem e espíritos do mal -, a natureza na sua totalidade é permeada permanentemente de tensões, predações e ataques, que são equilibrados pelos espíritos bons e superiores sob o manejo dos sábios pajés. Este manejo da natureza e da vida obedece a um protocolo definido e conhecido pelos indígenas, principalmente pelos sábios. Aliás, curar uma doença por meio do ritual proferido por um pajé é por em prática este protocolo de relações primordiais de respeito. Para cada situação ruim existe um protocolo próprio para cura e superação. Uma coisa é curar uma doença de uma pessoa acometida por espíritos da floresta, outra é curar a escassez de peixe ou de caça em um terminado território, rio ou lago.

A ideia de educação para manejo do mundo e da vida é para contrapor à concepção do homem globalizado quando concebe a educação como necessidade instrumental para domínio, exploração, manipulação, subjugação e destruição da natureza, do mundo e da vida. O homem globalizado, mesmo com seu sofisticado aparato tecnológico, consegue explorar e destruir a natureza, mas nunca dominá-la ou sujeitá-la, porque ela possui espírito grande, forte e superior. As principais forças representativas e reativas da natureza não sofrem controle e 
domínio da ciência e tecnologias atuais, a exemplo dos raios, trovões, tempestades, furações, secas, enchentes etc.

Assim, conhecimento para o indígena é entender como a natureza funciona, para saber viver e conviver com ela, com respeito, com ética, sem transgredi-la. Seguindo este princípio filosófico básico garante-se saúde corporal e espiritual e as condições necessárias para uma vida boa, bem viver (MACAS, 2000). Cada ato simples e impensado que se pratica contra a natureza, ou seja, contra algum ser que compõe o mundo, pode ter sérias consequências para a vida do ser humano e para a natureza como um todo. Bem viver é a concepção e prática de vida indígena, predominantemente andina, que leva em consideração e a sério, a interdependência da natureza e do mundo. Nessa perspectiva filosófica e ontológica do bem viver, a vida é possível e boa, quando é para todos os seres, ou seja, um estado de equilíbrio e harmonia entre todos os seres, entre o homem e a natureza. Basta uma parte em desequilíbrio para impor coisas, fatos e eventos ruins a todos.

Conclui-se, com isso, que temos hoje duas maneiras de pensar muito distintas: o pensamento indígena que considera e trata a natureza como sua casa e da qual depende para existir e bem viver e o pensamento dominante no mundo globalizado que considera a natureza como objeto material, recurso econômico, sendo o homem o dono ou propriedade particular, ou seja, a natureza dependente do homem. Na academia é necessário saber lidar com as duas formas de pensamento com muito cuidado. Muito cuidado porque podemos inconscientemente e inconsequentemente ir substituindo os conhecimentos indígenas pelos conhecimentos científico da universidade. Deste modo, vamos submetendo os nossos povos ao domínio do conhecimento não indígena e, por tabela, ao poder político, cultural, econômico e religioso dos nossos colonizadores e dominadores.

Por isso, é necessária uma boa compreensão e consciência histórico-cultural de quem somos; de onde viemos; onde nos situamos e quais perspectivas coletivas dos nossos povos, mantendo nossos pensamentos ancestrais, nossas identidades, nossos conhecimentos e nossos modos de vida próprios. Acessar e dominar os conhecimentos não indígenas, especialmente os conhecimentos científicos não é uma coisa ruim em si mesma, ao contrário, é uma coisa boa e necessária, desde que seja para somar, complementar e fortalecer nossos conhecimentos próprios e ancestrais e nossas identidades e modos de vida. Nunca pode ser para substituir nossos saberes, valores e modos de vida, muito menos para negá-los ou interiorizá-los, pois se assim for, estaremos reproduzindo o que há de pior nas práticas coloniais, que é a visão de que ou não somos ou somos inferiores, humana, cultural e cognitivamente. 
Uma das maiores fragilidades dos povos indígenas de ontem e de hoje é não conhecer bem e a fundo o mundo do branco. Como ele funciona, quais os seus pensamentos, suas lógicas, seus valores ou contravalores, seus conhecimentos, seus interesses, suas artimanhas, suas estratégias, suas visões, seus ideais, seus jeitos, seus trejeitos, suas manhas, suas fortalezas, suas fraquezas. Não em busca de dominá-los ou subjugá-los, pois se assim fosse, estaríamos copiando tudo o que reprovamos neles. Mas conhecendo o mundo do branco ele se torna mais compreensível, inteligível, decifrável, previsível, portanto, manejável para nós. Decifrável e previsível para sabermos como dialogar, conviver, coexistir simetricamente ou pelo menos de formas menos assimétricas.

Essa compreensão de como funciona o mundo do branco e o mundo globalizado é essencial para a defesa e garantia dos nossos direitos coletivos indígenas, por meio de estratégias certas de diálogo e de lutas. É necessário, portanto, estudar e pesquisar o branco e o seu mundo para termos uma compreensão do seu modus operandi, sobre ele mesmo, mas, sobretudo sobre nós. $\mathrm{O}$ que ele pensa de nós. O que ele quer de nós, $\mathrm{O}$ que ele deseja para nós. O que ele deseja para ele e para o mundo. Sabemos muito pouca coisa do homem branco. Sabemos de coisas muito superficiais e artificiais do mundo globalizado e, por vezes, de formas equivocadas ou através de fake news. Sabemos o que ele nos diz, promete, idealiza. Mas uma das características dele é a perspicácia política onde quase tudo vale, inclusive, iludir. Referimo-nos ao mundo do branco, pois nossa maior preocupação é com o seu mundo, pelo que já nos fizeram e continuam fazendo, isso, é claro, sem desconhecer, a importância de outros mundos, dos negros, asiáticos e outros.

Sem conhecimento profundo sobre o mundo do branco, não temos como manejar o mundo dele e nem o nosso, porque o nosso está muito influenciado pelo dele. Por isso, muitas vezes nossas lideranças se iludem, se vendem e às vezes traem seu povo por ingenuidade ou por má fé, por não entenderem ou compreenderem as questões em jogo. O mundo do branco é muito complexo, burocratizado e institucionalizado, por isso, é necessário compreendê-lo bem. Todos os indígenas podem ir às universidades para compreendê-lo, mas não para serem dominados. Assim, é parte da missão de indígenas na escola e na universidade, além de afirmar, pesquisar, registrar e divulgar suas identidades, culturas, línguas e conhecimentos, também estudar, pesquisar e conhecer os códigos, os pensamentos e conhecimentos dos não indígenas.

A “objetividade" científica desvaloriza a relação orgânica dos povos indígenas com a natureza e isso os enfraquece interna e externamente. Assim, é importante os indígenas 
acessarem a universidade não para negar o pensamento e os conhecimentos ocidentais acadêmicos, pois estes também são muito importantes para o mundo por suas proezas, avanços e conquistas históricas, mas para oferecer outros pensamentos e conhecimentos e demonstrar que a universidade tem uma série de limitações e empobrecimento ao não reconhecer, considerar e promover também outros pensamentos e conhecimentos que podem fortalecer o seu papel e enriquecer ainda a riqueza da sabedoria humana na sua diversidade. Sem este reconhecimento de outras lógicas e racionalidades humanas, as universidades se tornam ou continuam sendo espaços de violência cultural, cognitiva e epistêmica ou como denomina Boaventura Souza Santos, Epistemicídio (SOUZA SANTOS, 2000).

No mundo atual liberal e globalizado, o predomínio da razão e a ruptura com a natureza marca a imposição de uma dualidade radical próprias do pensamento moderno europeu: natureza x cultura; sujeito $\mathrm{x}$ objeto; matéria $\mathrm{x}$ espírito; corpo x mente; razão $\mathrm{x}$ emoção; indivíduo x sociedade; ser x pensamento, dentre outras.

Um novo universo intersubjetivo vai se impondo, pautado pelos princípios da modernidade que, segundo Edgardo Lander, atuam como eixo articulador central dos conhecimentos científicos, desenvolvidos e definidos por quatro pressupostos básicos: a ideia de progresso; a naturalização das relações sociais e da natureza humana da sociedade liberalcapitalista; a ontologização das múltiplas separações próprias dessa sociedade, e a superioridade dos conhecimentos científicos dessa sociedade em relação aos outros saberes (LANDER, 2000).

As ciências sociais ao adotarem essa referência universal da modernidade, deixando de fora a natureza, impõem essa cosmovisão liberal não permitindo a existência de outras lógicas e visões de mundo próprias e nem reconhecendo a sua contemporaneidade (LANDER, 2000; PORTO-GONÇALVES, 2000). Pelo contrário, tendem a extinguir estas outras existências, como tem acontecido com os povos indígenas, configurando-se o que Boaventura de Souza Santos define como "epistemicídio".

El privilegio epistemológico que la ciencia moderna se concede a sí misma es, pues, el resultado de la destrucción de todos los conocimientos alternativos que podrían venir a enjuiciar ese privilegio. En otras palabras, el privilegio epistemológico de la ciencia moderna es producto de un epistemicidio. La destrucción del conocimiento no es un artefacto epistemológico sin consecuencias, sino que implica la destrucción de prácticas sociales y la descalificación de agentes sociales que operan de acuerdo con el conocimiento enjuiciado (SOUZA SANTOS, 2000, p. 276). 
Instrumento de dominação étnica/racial, o epistemicídio é conceito retomado por Sueli Carneiro que ressalta como este processo de destituição da racionalidade, da cultura e da civilização do Outro se inicia no período colonial e se consolida no século XIX, controlando mentes e corações, sendo uma "[...] forma de sequestro da razão em duplo sentido: pela negação da racionalidade do Outro ou pela assimilação cultural que em outros casos lhe é imposta [...]" (CARNEIRO, 2005, p. 97).

O conhecimento imposto e considerado como válido e verdadeiro legitima modos de vida pautados pela exploração e dominação que são aceitos pela grande maioria como única opção possível. Histórica e culturalmente se ensina a desconsiderar outros saberes, desqualificar seus detentores, e reproduzir as opressoras dinâmicas sociais sem críticas, sem referências para se buscar agir de outros modos.

Quem determina qual é o verdadeiro conhecimento? A quem ele serve? Até quando seguiremos seguindo seus fundamentos? O modelo civilizatório da modernidade que se apresenta como a única lógica possível vem sendo sustentado historicamente por todo o aparato do Estado e suas instituições, incluindo a universidade.

A ideia de que a ciência é a única portadora ou produtora de verdade enfraquece e complica muito a realidade dos povos indígenas. Por conta disso, os povos indígenas precisam compreender bem o pensamento ocidental para não se tornarem meros consumidores ou vítimas deles, mas também oferecer opções e alternativas de outros modos de pensamento e de vida diferentes e, assim, ajudar a construir uma sociedade mais plural, mais democrática, mais humana, mais intercultural e intercientífico. Precisamos pensar e construir novas e outras universidades no Brasil e no mundo abertas ao mundo na sua diversidade cultural, étnica, racial, cosmológica e ontológica.

A escola nos ajudou muito a compreender o mundo do branco, mas ajudou muito pouco na compreensão da relação do mundo do branco com o mundo indígena. Tivemos que aprender sobre essas relações históricas no percurso concreto da vida, muitas vezes de forma sofrida, dramática. Hoje, o movimento indígena tem se enfraquecido em suas lutas e uma das possíveis causas é pela incapacidade de fazer questionamentos sobre essas questões de fundo que permitiriam buscas por respostas e processos novos de relações com o mundo extraaldeia. Realidades extra-aldeias que afetam diretamente e de forma irreversível a vida nas aldeias.

O pensamento ocidental se considera autossuficiente e o único verdadeiro. $\mathrm{O}$ pensamento indígena não. Este utiliza a ideia de complementariedade de pensamento, o que 
significa admitir a necessidade de outros pensamentos e a limitação do seu próprio conhecimento. Por isso, vamos à busca dos conhecimentos científicos e de outros conhecimentos do mundo. Nós, povos indígenas, entendemos a necessidade de aperfeiçoamento constante de nossos conhecimentos que, aliás, é de ordem primordial, uma vez que a missão mais nobre recebida por ocasião da criação do mundo e dos seres - dentre eles, os humanos -, é o aperfeiçoamento do mundo criado, por meio do conhecimento. Conhecimento este que vem da natureza e sobre a própria natureza.

A ideia e proposta de interculturalidade (WALSH, 2010) têm sido propagadas na universidade, mas pouco praticadas ou vivenciadas. Processos de debates são ricos, animadores, mas ainda necessitam levar em consideração o campo da espiritualidade, que vem e está referenciada na natureza. No mundo atual globalizado, a espiritualidade está ligada ao sobrenatural, ao transcendente, a Deus que está muito distante da compreensão humana, portanto, não manejável. A espiritualidade indígena está ligada e é parte intrínseca do mundo natural, imanente, e, portanto, manejável, por meio do conhecimento. Acessível em benefício do homem e da natureza. Considerando essa perspectiva cosmológica, filosófica, ontológica e epistemológica indígena a atual escola indígena e a universidade pluricultural necessitam ser repensadas, ressignificadas e transformadas, pois ainda estão baseadas em conceitos ocidentais, portanto, empobrecidas e fora da realidade concreta da diversidade cultural humana e da própria natureza.

Nós, povos indígenas, devemos continuar buscando e lutando por espaços nas universidades e uma vez dentro delas, buscar contribuirmos na sua necessária transformação abrindo e garantindo espaços para outros pensamentos, conhecimentos e modos sustentáveis de vida, e diminuindo ou mesmo eliminando os pensamentos etnocêntricos dominantes e as práticas de epistemicídio (SOUZA SANTOS, 2000). É necessário compreender que para romper barreiras dentro da universidade exige um longo caminho de luta para quebrar a hegemonia do saber colonial e colonizador que já produziu tragédias humanas e naturais demais para continuar incólume, não para negá-lo ou destruí-lo, mas para possibilitar a continuidade de outros saberes, que ao longo de milhares de anos da história, possibilitaram o desenvolvimento de complexas, ricas e grandiosas civilizações humanas em todos os continentes do nosso belo planeta Terra.

Não se pode esquecer que isso tudo é uma luta política também, uma disputa de poder não só pela força, mas também pelas ideias. Seria muito bom fazer mais trocas de experiências entre nós, até para poder enfrentar o poder central de cada universidade. Não é 
mais possível admitir a subalternidade. Não se pode admitir que o mito seja subjugado a irracional ou o poder dos homens e do mundo sobre a natureza. Para nós indígenas o poder, enquanto capacidade de se estabelecer e fazer cumprir as regras no mundo, na natureza e na vida está inexoravelmente nas mãos da natureza, na sua organicidade e diversidade e não nas mãos das sociedades humanas, como a ciência política do mundo globalizado dominante, nos quer fazer crer a partir da ideia de contrato social (ROUSSEAU, 1999).

O contrato de convivência e de governança global indígena não é apenas social, é também, e, sobretudo, com o mundo, com a natureza, portanto, cósmico ou cosmopolítico. Usamos a noção de cosmopolítico no sentido próprio de política do cosmo ou política que engloba ou feita por todos os seres do cosmo. Mesmo quando o poder localizado está em mãos humanas este depende da natureza, ou seja, o poder será limitado por ela. Nosso contrato não é social, é cósmico, é com a natureza. De fato, por mais poderoso que possa parecer um governante em sabedoria, riqueza, armas e soldados, este se inclina diante de uma simples ação ou reação da natureza. Neste sentido, Stavenhagem nos lembra que em "contra quinientos años del olvido, los indígenas desafiam ahora al mundo y a las ciências sociales con um mundo em que quepan todos los mundos” (STAVENHAGEN, 2010, p. 27).

\section{Considerações finais}

É preciso pensar a educação escolar ou universitária de indígenas na perspectiva de uma possibilidade ou capacidade de manejo do mundo que também implica na necessidade de, a partir deste manejo cósmico, domesticar o mundo humano dominante e hostil da escola e da universidade, do ponto de vista indígena. A arquitetura conceitual das ideias de manejo e domesticação do mundo serve para sair da famigerada linha de pensamento dominante de dualismo índio versus branco, conhecimento tradicional indígena versus conhecimento científico, mundo indígena versus mundo do branco que, definitivamente, por um lado, não representa o pensamento indígena na contemporaneidade, ainda que na sua heterogeneidade e singularidade e, principalmente, não ajuda na construção de um horizonte intercultural do mundo desejável.

O dualismo de oposição em si nos conduz ao fim trágico da história, pois não haveria saída para os sujeitos diferentes da história, humanos e não humanos. Optamos por acreditar que a humanidade e o mundo podem ter futuro sim nas suas e com as suas diversidades, sem, portanto, negar nenhuma de suas partes, por mais simples que sejam. Os pensamentos 
indígenas e as ricas experiências existenciais que esses pensamentos genuínos dos nossos ancestrais possibilitaram construir e viver ao longo de milhares de anos são provas contundentes de que o capitalismo, o neoliberalismo e a teologia do desenvolvimentismo (des ou anti)humano e (des ou anti)natureza não são de longe as únicas formas de existência e de vida, nem hoje, nem nunca.

Pode ser utopia, mas o pensamento indígena alimentado pela possibilidade de domesticação humana e cósmica pelo viés da sabedoria e da agencialidade da mãe natureza, dá sentido e razão existencial para que os povos indígenas continuem suas lutas por seus direitos à existência e à vida. Desse direito e valor, eles não estão dispostos a abrir mão, como não abriram mão em nenhum momento durante os 519 anos de tentativas de dominação e extermínio colonial. Esta perspectiva de protagonismo da natureza por meio do manejo e domesticação pedagógica e filosófica do homem, talvez seja a única saída para o mundo humano perdido em sua vaidade, ambição, arrogância e traição, a quem o possibilitou existir, a natureza, tão maltratada em nossos tempos.

Concluo esta comunicação com o pensamento muito oportuno de Souza Lima:

Educação para manejo do mundo é, sobretudo, uma prova de que do árduo processo de domesticação podem-se afirmar a independência do pensar e novas bases para a ação transformadora (SOUZA LIMA, 2013, p. 17).

\section{Referências bibliográficas}

CARNEIRO, Aparecida Sueli. A construção do outro como não-ser como fundamento do ser. Feusp, 2005.

ESCOBAR, Arturo. O lugar da natureza e a natureza do lugar: globalização ou pósdesenvolvimento? En libro: A colonialidade do saber: eurocentrismo e ciências sociais. Perspectivas latino-americanas. Edgardo Lander (org). Colección Sur Sur, CLACSO, Ciudad Autónoma de Buenos Aires, Argentina. Setembro 2005. p. 133-168.

LANDER, Edgardo (editor). La colonialidad del saber: eurocentrismo y ciencias sociales. Buenos Aires: Unesco/Clacso/Faces UCV, 2000.

LEVI-STRAUSS, Claude. O pensamento selvagem. Campinas: Papyrus, 1989.

LUCIANO, Gersem dos Santos. O Índio Brasileiro: o que você precisa saber sobre os povos indígenas no Brasil de hoje. Brasília: Ministério da Educação, Secretaria de Educação Continuada, Alfabetização e Diversidade; LACED/Museu Nacional, 2006. 
LUCIANO, Gersem J. dos Santos. A educação como manejo do mundo: entre a escola ideal e a escola real. Rio de Janeiro: Contracapa; Laced, 2013.

MACAS, Luis. Sumak Kawsay: la vida en plenitud. In: América Latina en movimiento no 452. Fevereiro de 2010.

MIGNOLO, Walter. Desobediência epistêmica: a opção descolonial e o significado de identidade em política. Cadernos de Letras da UFF - Dossiê: Literatura, língua e identidade, n. 34, p. 287-324, 2008.

PORTO-GONÇALVES, Carlos Walter. La colonialidad del saber: eurocentrismo y ciencias sociales. Presentación a la edición brasileña. Buenos Aires: Unesco/Clacso/Faces UCV, 2000.

ROUSSEAU, J-J. O contrato social. In: Oeuvres completes, tome III. Collection "Pléíade". Paris: Gallimard, 1757.

ROUSSEAU, J-J. Discurso sobre a origem e os fundamentos da desigualdade entre os homens. São Paulo: Nova Cultural, 1999;

SOUZA LIMA, Antônio Carlos. A domesticação do mundo. Prefácio do Livro A educação como manejo do mundo: entre a escola ideal e a escola real, de LUCIANO, Gersem J. dos Santos. Rio de Janeiro: Contracapa; Laced, 2013.

SOUZA SANTOS, Boaventura. Crítica de la razón indolente. Contra el desperdício de la experiencia. Vol. 1. Para un nuevo sentido común: la ciencia, el derecho y la política en la transición paradigmática. Palimpsesto Derechos Humanos y Desarrollo. 2000.

STAVENHAGEN, Rodolfo. Repensar América Latina desde la subalternidad: el desafío de Abya Yala In: Los pueblos originarios: el debate necessário. Compilado por Norma Fernández. - 1a ed. - Buenos Aires: CTA Ediciones: CLACSO: Instituto de Estudios y Formación de la CTA, 2010.

WALSH, Catherine. Interculturalidad crítica y educación intercultural. In: Construyendo Interculturalidad Crítica. La Paz: III - CAB, 2010.

Submetido em 17 de junho de 2019.

Aceito em 05 de agosto de 2019.

Publicado em 05 de agosto de 2019. 